\title{
JURISDIÇÃO INTERNACIONAL NO ÂMBITO DO MERCOSUL
}

Flávio Augusto de Oliveira Santos

SUMÁRIO: 1. Introdução. 2. Ambito de aplicação, 3. Determinações gerais sobre a jurisdição. 4. Local de cumprimento do contrato. 5. Domícilio do demandado. 6. Reconvenção. 7. Disposições finais. 8. Conclusão. 9. Bibliografra.

SUMMARY: 1. Introdution. 2. Scope of application. 3. General determination on jurisdiction. 4. Place of fulfilment of contract. 5. Domicile of demanded the 6. Reconvention. 7. Final disposals. 8. Conclusion. 9. Bibliography.

SUMARIO: 1. Introducción. 2. Ámbito de aplicación. 3. Determinaciones generales sobre la jurisdicción. 4. Local de cumplimento del contracto. 5. Domicilio del demandado. 6. Reconvención. 7. Disposiciones finales, 8. Conclusión. 9. Bibliografia.

RESUMO: Diante de um cenário tão complexo como o do Mercado comum, é natural que os conflitos juridicos assumam dimensões que extrapolem fronteiras fisicas entre nações, e que a solução para tais conflitos deva ser buscada por meio veloz, para integrar jurisdiçôes de Estados diversos. E foi exatamente com essa mentalidade que os Estados-Partes do MERCOSUL firmaram o Protocolo de Buenos Aires, que regulamenta o funcionamento de uma jurisdiça internacional para o referido bloco. Entretanto, uma efetiva e vantajosa jurisdição internacional depende da supranacionalidade das instituições mercosulinas. 
ABSTRACT: Analysing the Common Market, it is natural that legal conflicts assume dimensions that surpass physical borders between nations, and that the solution to such conflicts must be searched quickly, to integrate jurisdictions of diverse States. And with this mentality MERCOSUR's Member States had firmed the Protocol of Buenos Aires, that regulates the functioning of an international jurisdiction. However, an effective and advantageous international jurisdiction depend on the suptanationality of the MERCOSUR's institutions.

RESUMEN: Delante de una escena tan compleja como el Mercado Común, es natural que los conflictos legales asumen las dimensiones que sobrepasan las fronteras fisicas entre las naciones, y que la solución para tales conflictos debe ser buscada rápidamente, para integrar jurisdicciones de diversos estados. $E$ exactamente con esta mentalidad que los Estados-Partes del MERCOSUL habian firmado el Protocolo de Buenos Aires, que regula el funcionamiento de una jurisdicción internacional. Sin embargo, una jurisdicción internacional eficaz y ventajosa depende de la supranacionalidad de las instituciones del MERCOSUR.

PALAVRAS-CHAVE: Jurisdição. MERCOSUL. Supranacionalidade.

KEY-WORDS: Jurisdiction. MERCOSUR. Supranacionality.

PALABRAS-LLAVE: Jurisdicción. MERCOSUR. Supranacionalidad.

\section{Introdução}

O MERCOSUL, como instituição, e, portanto, objeto de formulações jurídicas, tanto no campo normativo interno e internacional quanto no âmbito doutrinário e de jurisprudência, já é uma realidade. Certamente, esta realidade ainda apresenta seus problemas, os quais se devem, entre outros fatores, à velocidade com que foi instituída, e mesmo desenvolvida. Os países que hoje integram o MERCOSUL, não tinham, 
e em muito ainda não têm, o preparo, por exemplo, dos países europeus para lidar com um processo de integração internacional ${ }^{1}$, o qual se apresenta como fruto, principalmente, das modificações sócioeconômicas deflagradas a partir da Segunda Guerra Mundial, e que caracterizaram a formação da atualmente chamada sociedade pós-moderna $^{2}$.

No entanto, é compreensível que a realidade mundial exigia, como exige, providências urgentes em face das transformações econômicas, em curso quase que diariamente. Países como Brasil, Argentina, Uruguai e Paraguai, que têm economias internas relativamente fracas, se comparadas, por exemplo, à dos Estados Unidos da América do Norte, precisavam efetivamente, se unir, o mais rápido possível, para enfrentar os desafios de um mundo que se internacionaliza dia a dia, e se divide em blocos econômicos cada vez mais abrangentes e mais fortes.

Diante de um cenário tão complexo, considera-se natural que conflitos jurídicos assumam dimensões que extrapolem fronteiras fisicas entre nações, e que a solução para tais conflitos deva ser buscada através de uma forma, o mais veloz possível, de integrar jurisdições de Estados diversos, principalmente num espaço integrado que pretende atingir, futuramente, o status de Mercado Comum.

E foi exatamente com essa mentalidade que os Estados-Partes do MERCOSUL firmaram, em 05 de agosto de 1994, o Protocolo de Buenos Aires, centro da regulação do funcionamento de uma jurisdição internacional para o referido bloco econômico.

\section{2. Âmbito de aplicação}

O Protocolo de Buenos Aires destina-se, fundamentalmente, a regulamentar a jurisdição internacional, para solução de controvérsias que envolvessem contratos internacionais de natureza civil ou comercial, celebrados por particulares, pessoas fisicas ou jurídicas, domiciliados ou com sede social $\mathrm{em}$ países diferentes, desde que pelo menos uma das partes contratantes tenha seu domicilio ou sede social em um Estado Parte do MERCOSUL. Outra exigência para que se aplique o Protocolo

\footnotetext{
'Cf AMIN, E. O Direito no MERCOSUL. Brasília: Senado Federat, 190\%,

"Ct KUMAR, K Da sociedade pós-industrial à pós-moderna - Novas teorias sobre o mundo contemporâneo. Rio de Janeiro: Jorge Zahar, 1997, pp. 39-44.
} 
de Buenos Aires é que as partes, através de cláusula de eleição de foro, tenham convencionado como válida para solucionar os conflitos decorrentes de seu contrato a jurisdição ordinária ou arbitral de um dos Estados Partes, bem como se apresente razoável conexão entre a matéria contratada e foro escolhido, na forma do referido Protocolo. Quanto a este último critério, qual seja o da conexão razoável, a doutrina vem tecendo crítica no sentido de que, neste Protocolo, o mesmo se aplica como requisito determinante do âmbito de aplicação do Tratado, dando lugar a que sua ausência implique em eventuais decisões segundo o Direito Internacional Privado da cada Estado-Parte, o que possibilitaria séries de decisóes sem a uniformidade pretendida no Mercado Comum. Por outro lado, se a conexão razoável fosse condição de validade do próprio acordo de eleição de foro, sua ausência invalidaria, de pleno direito, o acordo em si, não cabendo posterior discussão, no âmbito interno de cada Estado membro, acerca de sua validade. Poder-se-ia, ainda, ter simplesmente suprimido este critério como requisito para a aplicação ou não deste Protocolo. Nesse sentido, atente-se para o seguinte comentário:

“...) la circunstancia de que se haya pactado la jurisdicción de un Estado miembro y de que una de las partes esté domiciliada en algún Estado parte del Tratado de Asunción, configuran por sí mismas conexión apropiada entre el proceso y el Protocolo de Buenos Aires. Hubiera sido preferible que estas dos condiciones se consideraran suficientes para determinar el ámbito de aplicación espacial del Protocolo de Buenos Aires".

Pelo exposto, percebe-se que o campo de aplicação do Protocolo ora em comento não é dos mais vastos. No entanto, em seu artigo segundo, as restrições à sua aplicação aumentam ainda mais. O referido dispositivo relaciona, de forma taxativa, as matérias e relações jurídicas em que se exclui a referida aplicação. Não se aplicam as normas do Protocolo de Buenos Aires às relações jurídicas entre falidos e seus credores, concordatários e seus credores e insolventes declarados e seus credores, por força do princípio da universalidade do Juízo da falência e procedimentos assemelhados. Porém, no que diz respeito à concordata preventiva, poderá haver essa aplicação quando discutidos os direitos dos credores com garantias reais ou fidejussórias ou dos credores decorrentes

TAQUELA, M. B. N. Los acuerdos de elecion de foro en el Protocolo de Buenos Arres de 1994. In IV Encuentro internacional de Derecho, p. 142. 
de relações instituídas após o deferimento do respectivo processamento, pois esses créditos escapam do processo de concordata. Estão excluídos, também, da aplicação do referido Protocolo todos os contratos ou acordos que tenham por objeto direito de família e de sucessões, vez que os mesmos são considerados direitos indisponíveis, aplicando-se-lhes as regras de jurisdição previstas nas legislações processuais internas. Quanto aos contratos de seguridade social, a não aplicação do protocolo de Buenos Aires resulta da própria natureza de direito público dessas relações. Idêntica razão exclui os contratos administrativos, de transporte e de seguros. Os contratos de trabalho, por também envolverem matéria de direito público, se sujeitam às regras de jurisdição do Estado Parte onde o trabalho é prestado. Também se submetem às normas internas de jurisdição os contratos relativos a direitos reais, ante o princípio universal do "foro do estado da coisa". E, por fim, excluem-se da jurisdição internacional os conflitos decorrentes de contratos de compra e venda ao consumidor, posto que se submetem à jurisdição do local da celebração do contrato.

\section{Determinações gerais sobre a jurisdição}

A jurisdição é conceituada como o poder / dever do estado de aplicar o direito vigente ao caso concreto. A jurisdição é exercida, ordinariamente, pelo Poder Judiciário. Extraordinariamente, a jurisdição poderá ser exercida por pessoas não integrantes do Poder judiciário, escolhidas entre particulares pelas partes envolvidas, a fim de compor as lides através da arbitragem. Para os efeitos do Protocolo de Buenos Aires, segundo determina seu art. 3a , estará cumprido o requisito processual da jurisdição internacional em matéria de contratos, desde que alguma autoridade judiciária de um estado parte se reconhecer competente para apreciar e julgar a controvérsia e assumir a jurisdição de acordo com as normas estatuídas pelo Protocolo de Buenos Aires. Isso não impedirá, todavia, que alguma das partes envolvidas no contrato excepcione e decline outro foro que entender competente.

As partes poderão acordar acerca da jurisdição escolhida para dirimir eventuais conflitos. Essa eleição da jurisdição poderá ser celebrada como cláusula do próprio contrato por elas celebrado, através de instrumento apartado durante a vigência do contrato, ou ainda por acordo, quando 
já deflagrado o litígio. $\mathrm{Na}$ hipótese de o contrato silenciar a esse respeito, a escolha do foro caberá ao demandante, que poderá optar pelo Juízo do lugar de cumprimento do contrato, pelo do domicílio do demandado ou pelo de seu próprio domićlio ou sede social. Neste último caso, deverá demonstrar que cumpriu com sua obrigação. Mas se, mesmo assim, restarem dúvidas sobre as normas a reger a jurisdição, será aplicado o direito mais favorável à manutenção do acordo firmado.

Vale ressaltar, ainda, que se a eleição de foro houver sido obtida de forma abusiva por alguma das partes, poderá ser anulada por conter vício de vontade. A parte que se sentir prejudicada pela abusividade com que se fez constar a jurisdição eleita no contrato, poderá pleitear essa anulação através de exceção de incompetência, indicando o Juízo ao qual declina. De outra parte, quando absoluta a incompetencia, poderá invocá-la em sede de ação rescisória. Poderão as partes, no contrato ou em documento apartado, optar pela arbitragem. Nesse caso, indicarão o árbitro ou o Tribunal Arbitral encarregado da solução de eventuais controvérsias e, também, as normas a serem observadas na arbitragem.

Já o artigo $6^{\text {a }}$ do Protocolo de Buenos Aires prevê a possibilidade de prorrogação da competência, na medida em que permite ao demandado em foro não eleito, ou diverso daquele determinado pelo contrato, concordar, expressamente, com a continuidade do processamento da demanda, até final julgamento, no Estado Parte onde se procedeu à sua proposição, desistindo do foro que, nos termos do mencionado Protocolo, ou mesmo do próprio instrumento contratual, seria competente para tanto. Diante dessa previsão legal, não cabe ao Juízo incompetente, perante o qual foi proposta a ação, declarar, ex officio, sua incompetência, sem a oitiva, a esse respeito, do demandado. No entanto, se a incompetência for excepcionada, acatará, desde que efetivamente procedente, essa exceção. Haverá prorrogação apenas nos casos de concordância expressa e voluntária do demandado em relação à mesma, sob pena de se ver declarada a incompetência do Juízo prorrogado.

\section{Local de cumprimento do contrato}

Será considerado lugar de cumprimento do contrato, para fins de fixação da jurisdição, o Estado Parte em cujo território deva ser cumprida a obrigação em que se fundamente a demanda. Se o contrato recair 
sobre coisas infungiveis, será considerado local de cumprimento da obrigação o lugar onde elas estavam ao tempo da sua celebração. Se, contudo, o contrato versar sobre coisas determinadas pelo gênero, ou fungíveis, será considerado lugar do cumprimento da obrigação o Estado Parte do domićlio do devedor, quando de sua celebração. Versando o contrato de prestação de serviços sobre coisas, será considerado lugar de cumprimento da obrigação aquele onde essas coisas estavam quando de sua celebração. Se a eficácia do contrato estiver expressamente relacionada a algum local específico, este será seu lugar de cumprimento. Por fim, quando não se verificar nenhuma dessas hipóteses, será considerado lugar de cumprimento da obrigação referente à prestação de serviços o domicílio do devedor ao tempo da celebração do contrato.

\section{Domicílio do demandado}

Várias são as possibilidades de determinação, para efeitos da jurisdição internacional, do domicilio do demandado. Tratando-se de pessoa fisica, considerar-se-á seu domicílio o lugar onde haja fixado residência habitual, ou, não sendo possível determinar sua residência, o lugar onde houver estabelecido o centro principal de seus negócios. Não se podendo determinar nem mesmo este último, será considerado domicílio do demandado o lugar onde este for encontrado.

Em se tratando de pessoa jurídica, será considerado seu domicílio o lugar da sede principal de sua administração. Assim se passará, da mesma forma, quando a controvérsia decorrer de conflitos entre sócios e se relacionar a questões societárias. Todavia, a pessoa jurídica poderá igualmente ser demandada no foro do local onde funcione uma de suas sucursais, filiais, agências, estabelecimentos ou representações, quando o litígio versar sobre contratos ali praticados.

Não restando contratualmente estabelecido o foro, a pessoa jurídica, independente de onde se localize sua sede, poderá ser demandada no foro de domicílio do demandante, mesmo este não demonstrando o cumprimento de sua prestação. Da mesma forma, quando houver pluralidade de demandados, poderá se estabelecer o litígio no Estado Parte de domicílio de qualquer deles. Bem assim, nos casos em que a demanda se relacionar ao cumprimento de obrigações resultantes de garantia pessoal, ou visar à intervenção de qualquer qualidade de terceiros no processo, poderá ser proposta perante o Juizo que estiver conhecendo do processo principal. 


\section{Reconvenção}

Nos termos do artigo 13 do Protocolo de Buenos Aires, o demandado poderá, no mesmo processo que contra ele for é movido, propor ação contra o demandante. No Direito brasileiro, esta figura jurídica recebe o nome de reconvenção. Não se trata de uma espécie de defesa do réu e, se a matéria em que se fundamentar seu pedido constituir, expressamente, matéria de defesa, será decretada a carência de reconvenção, inexistindo interesse processual, uma das condições da ação.

Um dos pressupostos da reconvenção é a sua conexão com a ação, tanto pela identidade da causa de pedir quanto pela identidade de objeto. Se a figura tradicional da reconvenção deve ser proposta nos mesmos Autos da ação, evidentemente será proposta, em se tratando da jurisdição internacional, perante a mesma autoridade judiciária que conhece da ação originária.

\section{Disposições finais}

O Protocolo de Buenos Aires é parte integrante do Tratado de Assunção, e, dessa forma, o Estado que aderir a este último estará, automaticamente, aderindo, de pleno direito, àquele. entrará em vigor trinta dias depois do depósito do segundo instrumento de ratificação com relação aos dois primeiros Estados artes que o ratifiquem. Para os demais signatários, entrará em vigor no trigésimo dia posterior ao depósito do respectivo instrumento de ratificação e na ordem em que forem depositadas as ratificações.

As eventuais controvérsias surgidas entre os Estados Partes acerca da aplicação, interpretação ou não cumprimento dos dispositivos do Protocolo de Buenos Aires serão solucionadas pela via diplomática direta. Não se obtendo sucesso por esse meio, a controvérsia será submetida ao Tribunal Arbitral, nos termos do capítulo IV do Protocolo de Brasília.

Ressalte-se, enfim, que o Governo da República do Paraguai, como depositário do Tratado de Assunção e de todos os atos dele derivados, notificará aos Governos dos demais Estados Partes, a data de entrada em vigor desse Protocolo e a data de depósito dos respectivos instrumentos de ratificação. 


\section{Conclusão}

Diante do exposto, tem-se que o Protocolo de Buenos Aires tem relevante posição no ordenamento jurídico do MERCOSUL, no sentido de manifestar a preocupação dos países envolvidos em estabelecer normas claras acerca do exercício da jurisdição além de suas fronteiras tradicionais.

No entanto, apresenta ainda suas incongruências, como, por exemplo, a opção pelo critério da conexão razoável como requisito de aplicação de suas disposições.

Por outro lado, o referido instituto encontra-se calcado numa estrutura institucional intergovernamental, o que acarreta não haver the restado grande espaço normativo para amenizar a burocracia natural das relações jurisdicionais internacionais. Isso se manifesta, sobretudo, na semelhança entre o sistema previsto nesse Protocolo e as normas gerais regulares da jurisdição internacional como um todo.

Assim, pode-se concluir que só se chegará a uma efetiva e vantajosa jurisdição internacional no bloco econômico ora sob análise quando se progredir em direção à supranacionalidade das instituições mercosulinas, até o nível em que se possibilite a criação de um Tribunal Supranacional para o Mercado Comum do Sul. Aqui, apresenta-se oportuna a seguinte lição da eminente jurista Luizella Giardino Branco:

"Não resta dúvida, portanto, que para a construção de um Mercado Comum se faz indispensável a criação de um Tribunal Supranacional, que funcione como principal impulsionador do processo integrador, zelando por sua lisura e garantindo sua duração".

Sobre a necessidade de se caminhar rumo à supranacionalidade de toda a estrutura institucional do bloco econômico, acrescenta Fúlvio Pretti:

"Como todos os órgãos do MERCOSUL, à exceção da Comissão Parlamentar Conjunta, são integrados por representantes dos governos dos Estados Partes, verifica-se que as decisões por ele tomadas resultam de vontades nacionais, quando, para a realização de uma perfeita $e$ profunda integração econômica, tais decisóes deveriam derivar de interesses e emanar de órgãos supranacionais".

\footnotetext{
- BRANCO, $L$ G. B. Sistema de Solução de Controvérsias no MERCOSUL - Perspectivas para a criação de um modelo institucional permanente. São Paulo: LT, 1997, p.168.

5 PRETT, Fûvo. MERCOSUL - A Instituiğo o Sistema de Soluça de Controversias. Blumenau: Editora da Fundaçấo Chiversidade Regional de Blumenall, 1999 , pp. 127.
} 
É claro que essa evolução deverá resultar de um processo lento e gradual, a ser realizado com base em intensa vontade política dos Estados-Partes ${ }^{6}$, mas certamente trará a recompensa de se passar a lidar não só com uma jurisdição internacional mais ágil e mais eficiente dentro do espaço integrado, mas também com uma integração sócio-econômica muito mais intensa e proveitosa para todos os interessados.

\section{BIBLIOGRAFIA}

AMIN, E. O Direito no MERCOSUL. Brasília: Senado Federal, 1998. KUMAR, K. Da sociedade pós-industrial à pós-moderna - Novas teorias sobre o mundo contemporâneo. Rio de Janeiro: Jorge Zahar, 1997, pp. 3944. TAQUELA, M. B. N. Los acuerdos de eleccion de foro en el Protocolo de Buenos Aires de 1994. In: IV Encuentro internacional de Derecho, p. 142. BRANCO, L. G. B. Sistema de Solução de Controvérsias no MERCOSUL - Perspectivas para a criação de um modelo institucional permanente. São Paulo: LTr, 1997, p.168.

PRETTI, Fúlvio. MERCOSUL - A Instituição e o Sistema de Solução de Controvérsias. Blumenau: Editora da Fundação Universidade Regional de Blumenau, 1999, pp. 127.

BAZÁN, V. El Mercosur desde el plano de las Constituiciones se sus Estados Partes: perspectivas Del sistema de solução de controversias. In PIMENTEL, L. O. Direito da Integração e Relaçôes Internacionais - Alca, Mercosul, EU.Florianópolis: Fundação Boiteux, 2001, pp. 670-682.

"BAZAN, V. El Mercosur desde el plano de las Constituiciones se sus Estados Partes: perspectivas Del sistema de solução de controversias. In PMMENTEL, L. O. Direito da Integração e Relaçôes Internacionais - Alca, Mercosul, EU. Flordanópolis; Fundaçâo Boiteux, 2001, pp. 670682. 